Textures and Microstructures, Vol. 31, pp. 239-248 Reprints available directly from the publișer Photocopying permitted by license only
(C) 1999 OPA (Overseas Publishers Association) N.V. Published by license under the Gordon and Breach Science Publishers imprint. Printed in Malaysia.

\title{
VOLUME TEXTURE OF A DEFORMED QUARTZITE OBSERVED WITH U-STAGE MICROSCOPY AND NEUTRON DIFFRACTOMETRY
}

\author{
H. GHILDIYAL ${ }^{a}$, E. JANSEN ${ }^{\text {b } * *}$ and A. KIRFEL ${ }^{\text {b }}$ \\ ${ }^{a}$ Mineralogisches Institut der Universität Würzburg, Germany; \\ ${ }^{\mathrm{b}}$ Mineralogisch-Petrologisches Institut der Universität Bonn, Germany
}

(Received 5 February 1999)

The volume texture of a naturally deformed quartzite from the Kaoko belt, North-West Namibia, has been analysed by both universal stage microscopy and neutron diffraction. Universal stage microscopy is restricted to the determination of the base pinacoid preferred orientation in quartzite. For a more complete description of the texture, the orientations of additional crystal planes, such as first and second order prisms as well as positive and negative rhombs, must be known. Neutron methods allow the evaluation of pole figures of all Bragg reflecting planes, of which those of the first order prisms being considered to be the most active slip planes, are of particular interest. Drawbacks of neutron diffraction, i.e. the faking of an eventually absent inversion centre and lack of resolution, can be overcome by pole figure inversion and subsequent calculation of desired pole figures. Both, universal stage microscopy and neutron diffraction yield well comparable results, of course only with respect to the pole figure of the $c$-axis.

Keywords: Neutron diffraction; U-stage microscopy; Quartzite texture

\section{INTRODUCTION}

The understanding of the crystallographic preferred orientation (CPO; also referred to as 'texture' in this contribution) of the component

\footnotetext{
*Corresponding author. Forschungszentrum Jülich, MIN-ZFR, D-52425 Jülich, Germany.
} 
minerals in a deformed rock is of great practical interest. According to Wenk and Christie (1991) and others it may provide information about:

- the active deformation mechanism (e.g. dislocation creep versus diffusion),

- the strain ellipsoid shape (oblate, plane, prolate strain geometry) and to some extent the magnitude of the finite strain, and

- the kinematic framework (coaxial versus non-coaxial deformation paths).

The most common mineral used for CPO analysis in crustal rocks is quartz due to its widespread occurrence and simple optical properties. The quartz $c$-axis is the only crystallographic direction that can readily be measured optically on an universal stage (U-stage). X-ray texture goniometer techniques have been used to work on the complete understanding of the textures of quartz crystallites in deformed rocks by providing information on their orientations exceeding that of $c$-axes patterns (e.g. Schmid and Casey, 1986). A modern technique in this field is the use of neutron diffraction with position sensitive detectors (PSDs). This method records for each sample orientation a whole diffraction pattern, from which subsequently the intensities of single peaks are extracted by deconvolution methods (Wenk et al., 1986).

Neutron diffraction is an attractive tool in texture analysis because, for neutrons, the transparency of matter is very high. For most elements, the neutron absorption coefficient is smaller than that for X-rays by about four orders of magnitude. Therefore, in neutron diffraction, complete pole figures can be measured in transmission geometry, allowing the investigation of irregular shaped samples with volumes up to some $\mathrm{cm}^{3}$. Sufficient grain statistics is achieved even in the case of coarse grained geological specimens (Wenk et al., 1984), and absorption effects are mostly negligible. There are no angle dependent defocusing effects as known from X-ray pole figure scanning. In addition, the use of PSDs allows simultaneous measurements of several pole figures (Wenk et al., 1986). The advantages of using PSDs and subsequent peak deconvolution methods in the texture analysis of multiphase and lowsymmetry materials have been discussed elsewhere (Merz, 1991; Schäfer et al., 1991). 
In the present contribution, optical U-stage microscopy and neutron PSD diffractometry have been used for studying a deformed quartzite from the Pan-African Kaoko belt in North-West Namibia.

\section{GEOLOGY AND MICROSTRUCTURES}

The quartzite sample HK 407 was collected from the late Proterozoic to early Palaeozoic (Pan-African) Nosib quartzite of the Tomakas area in the Kaoko belt, North-West Namibia. The quartzite is in contact with basement gneisses of Archean age (Seth et al., 1998; Franz et al., 1999). The Nosib quartzite was deformed and sheared, together with the basement gneiss, under upper-greenschist to lower-amphibolite facies metamorphic conditions, during the Pan-African Orogeny about 560 million years ago (Dingeldey, 1997). The rock exhibits a NW trending strong linear fabric $\left(309^{\circ} / 28^{\circ}\right)$ and a moderately dipping foliation plane $\left(299^{\circ} / 30^{\circ}\right)$.

The sample contains quartz (90-95\%), albite (4-5\%), and about $1-2 \%$ accessory minerals including biotite, opaques and a few crystals of apatite. The microstructures indicate syn- to post-tectonic recrystallisation leading to a spectrum of grain size from 0.03 to $0.83 \mathrm{~mm}$. In general, the grains show straight and annealed grain boundaries. Deformation bands are common. The mineral grains show a sharp preferred orientation in the lineation direction (Fig. 1).

\section{ANALYTICAL AND EXPERIMENTAL TECHNIQUES}

The pinacoid planes $\{c\}$ of 153 quartz grains were measured with the help of a 4-axis universal (Fedorov) stage, following the method described by Turner and Weiss (1963). The poles of the $c$-axes were plotted in a lower hemisphere, equal area stereo-net (Schmidt net) and contoured according to the technique proposed by Kamb (1959) using the computer program SPHERISSTAT (Fig. 2). The pole figure has the foliation plane (Sf) striking vertically $\mathrm{E}-\mathrm{W}$ and the stretching lineation (L) trending East; the inset in Fig. 2 shows the corresponding coordinates in a geographic reference frame. 


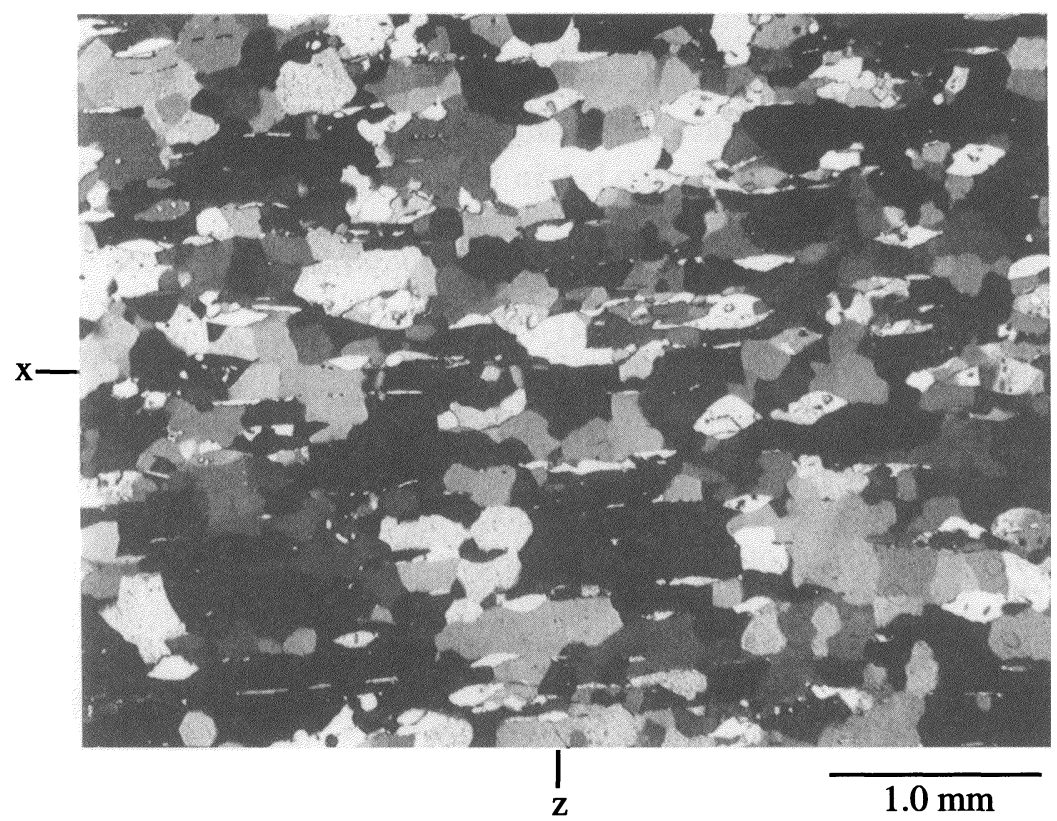

FIGURE 1 Photomicrograph of the analyzed quartzite specimen HK407. The section is perpendicular to the foliation ( $Z$ normal to foliation) and parallel to the lineation $X$. (Photograph under crossed polars.)

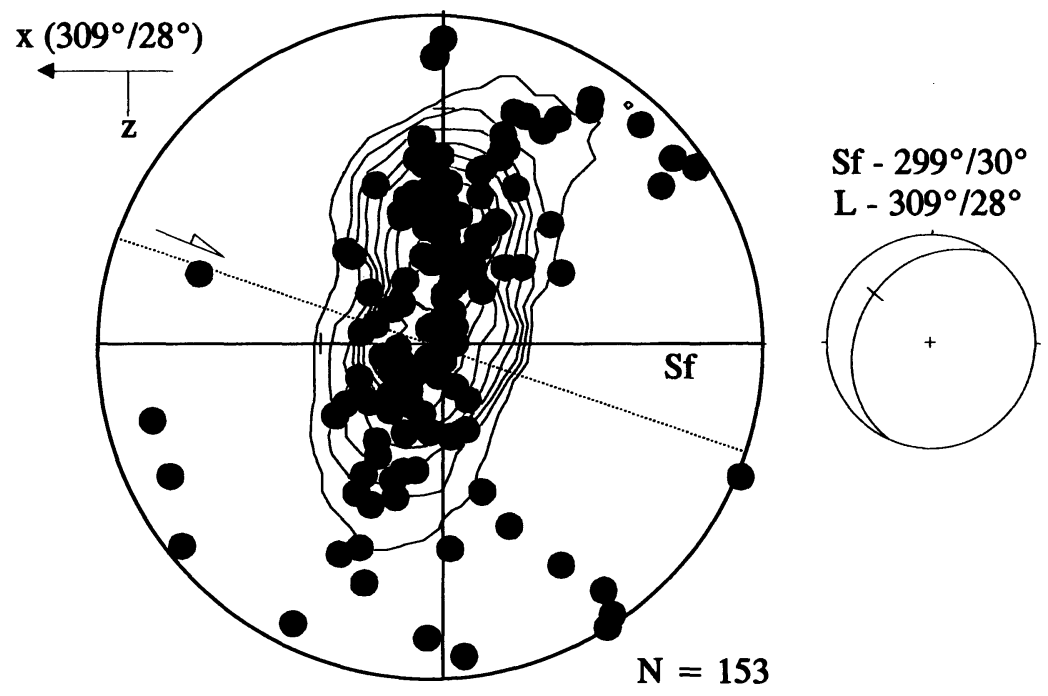

FIGURE $2 c$-axis pole figure parallel to Fig. 1 (lower hemisphere) obtained by U-stage measurements. The inset shows the samples orientation in the geographic reference frame. 
The neutron pole figure measurements were performed on the University of Bonn texture diffractometer at the FRJ-2 reactor in the Forschungszentrum Jülich (Schäfer et al., 1997). The diffractometer is equipped with one unit of the JULIOS PSD (Schäfer et al., 1995) covering a $2 \theta$-section of $43^{\circ}$ at a distance of about $100 \mathrm{~cm}$ from the sample. The position resolution of the detector is $4 \mathrm{~mm}$ corresponding to an angular resolution of about $0.23^{\circ}$. The neutron wavelength was $1.200(2) \AA$. The sample was mounted on a standard Eulerian cradle in normal-beam equatorial geometry using the angles $2 \theta, \omega, \chi$ and $\varphi$ as defined in the International Tables for Crystallography (1995). With a $2 \theta$-resolving PSD the $\chi$-circle is generally not in the bisecting position between incident and diffracted beam, and therefore the angles $\chi, \phi$ do not directly correspond to the pole figure coordinates $\alpha, \beta$ (Wenk et al., 1986). The necessary conversion is described by Bunge et al. (1984). Due to this conversion, a scan over points regularly spaced in $\chi$ and $\varphi$ results in $\alpha, \beta$ points irregularly spread over the pole figure. From these, an equispaced $5 \times 5^{\circ} \alpha, \beta$-grid containing the pole densities in units of multiples of random distribution (mrd) is obtained by interpolation. The pole figure determinations are based on integrated intensities purged from background effects. The sample orientation in the geographic reference frame is the same as for the $U$-stage measurement.

The neutron diffraction experiment was performed on an almost cubic sample of dimensions $2 \times 2 \times 2 \mathrm{~cm}^{3}$. Absorption and extinction effects arising from the geometry of the fairly large sample could be neglected. The measurements were carried out by raster scanning the sample in $\omega, \chi$, and $\phi$ with a total of 474 different sample orientations. For each orientation, the sample was exposed for $150 \mathrm{sin}$ which a diffraction pattern was recorded that covered $d$-spacings between 1.2 and $5.8 \AA$. The total time for the measurements was $20 \mathrm{~h}$. In the course of the data evaluation, the integrated intensities extracted from all diagrams were combined to provide fourteen well resolved pole figures, depicted in Fig. 3.

Since the Bragg reflections of the basal pinacoid planes $\{c\}$ were very weak and/or strongly overlapped by other reflections, the orientation distribution of the $c$-axes could not be directly derived from the observations. This problem was, however, circumvented by calculating the orientation distribution function (ODF) from the three pole figures shown in the top row of Fig. 4, i.e. the $\{10 \overline{1} 0\}$ pole figure describing the CPO of the first order prism $\{m\}$, the $\{10 \overline{1} 1+01 \overline{1} 1\}$ pole figure of the 

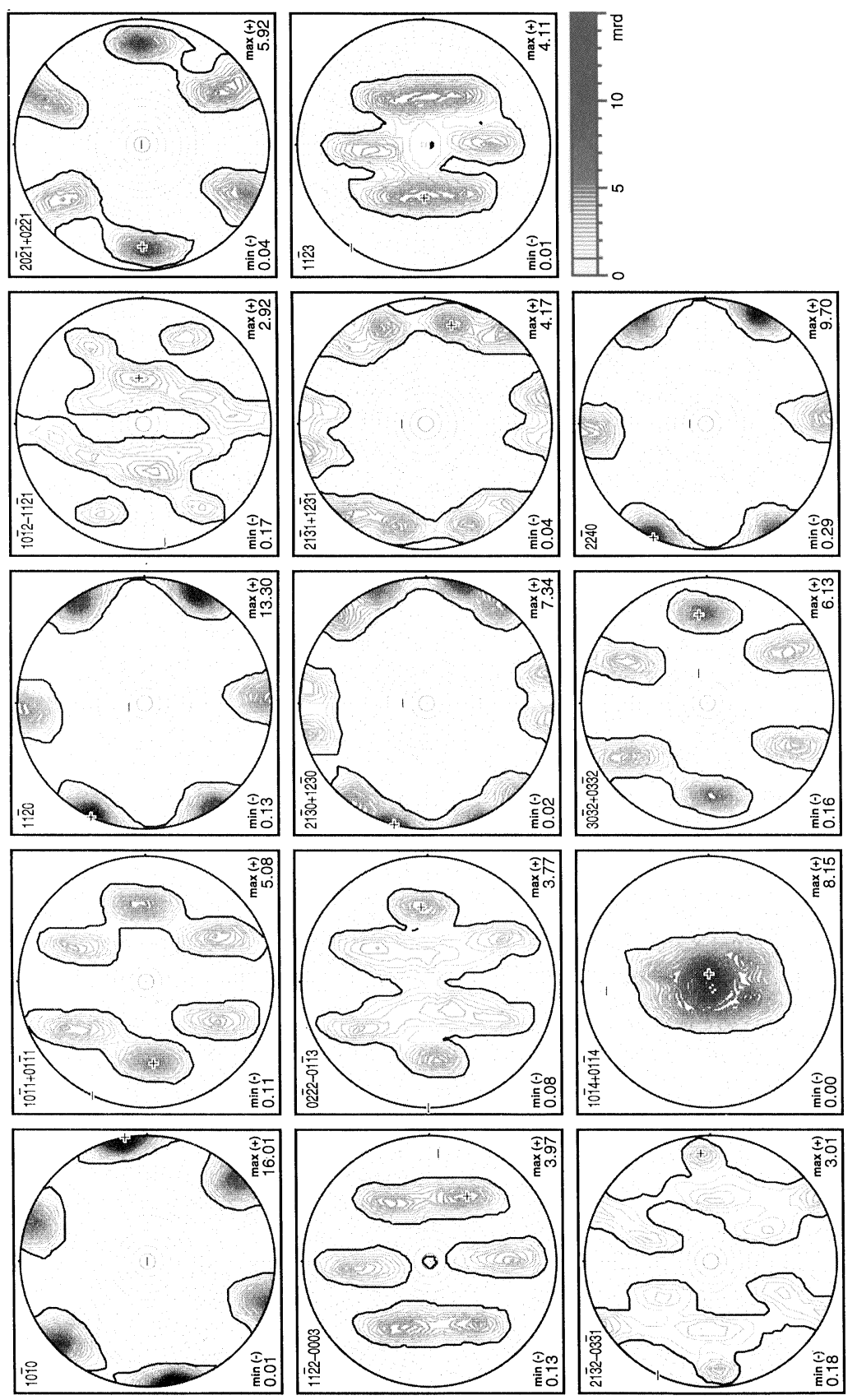

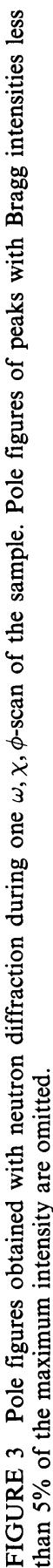



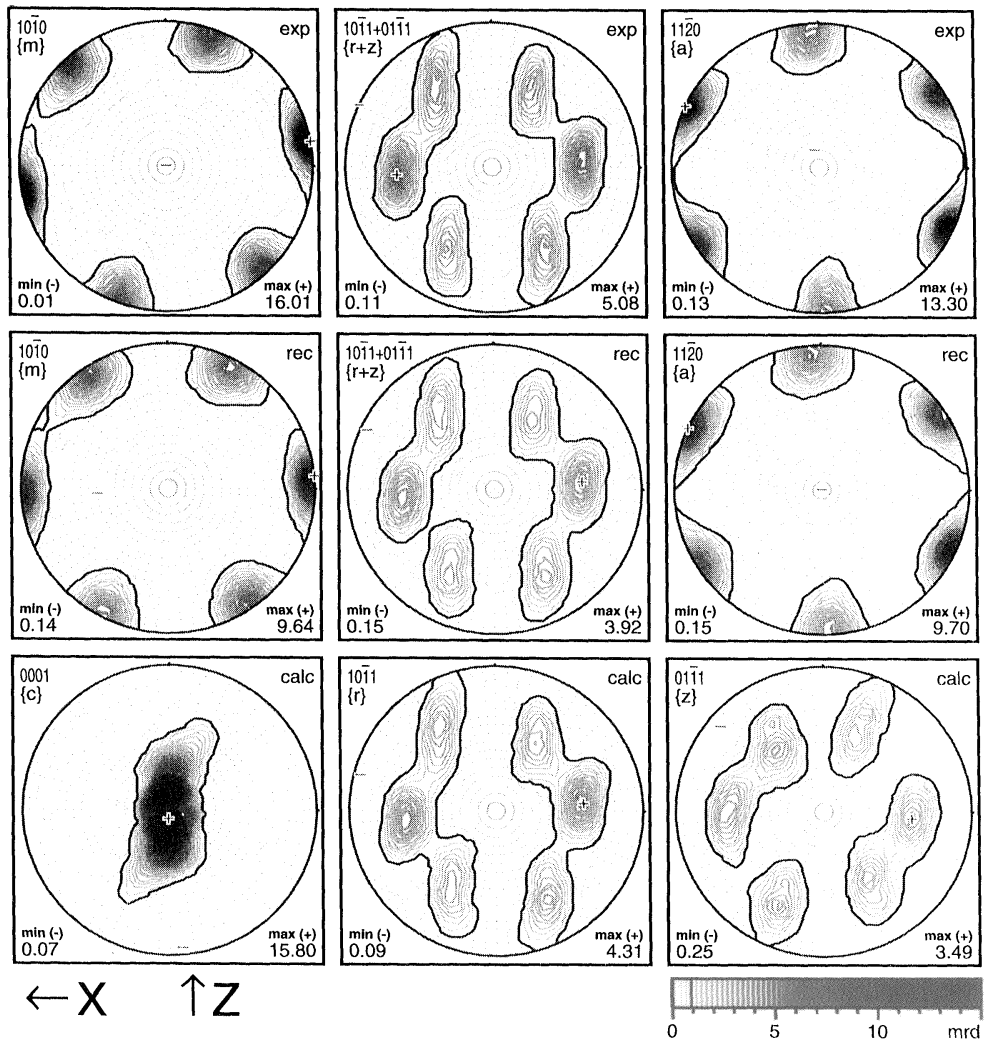

FIGURE 4 Observed and calculated neutron pole figures ( $X, Z$ : see Fig. 1). Top row: experimental pole figures $\{m\},\{r+z\}$ and $\{a\}$ (ODF input). Second row: corresponding model pole figures recalculated from the ODF. Bottom row: calculations of the 'unobserved' pole figures $\{c\},\{r\}$ and $\{z\}$.

intrinsically overlapped positive and negative rhombs $\{r\}$ and $\{z\}$, and the $\{11 \overline{2} 0\}$ pole figure of the second order prism $\{a\}$. This ODF-calculation was performed using the program MENTEX (Schäben, 1994). For comparison, the above pole figures recalculated from the ODF are depicted in the second row of Fig. 4, showing good agreement with those of the the top row. The bottom row contains calculations of the 'unobserved' pole figures of the base pinacoid $\{c\}$, and of the separated positive and negative rhombs $\{r\}$ and $\{z\}$. It should be noted that the $\{c\}$ pole figure (Fig. 4, bottom left) is in good agreement with that obtained by U-stage microscopy (Fig. 2). 


\section{POLE FIGURE INTERPRETATION}

The observed girdle distribution is interpreted with respect to a $X Y Z$ strain reference frame, where $X$ represents the axis of maximum elongation and $Z$ the direction of maximum shortening (Fig. 2). The $\{c\}$ pole figure shows a concentration of $c$-axes around $Y$ and a girdle close to the $Y Z$-plane. The tilt of the girdle against the foliation plane indicates a component of non-coaxial strain in the overall flow (e.g. Burg and Laurent, 1978; Simpson, 1986; Schmid and Casey, 1986). In combination with the orientation of foliation and lineation, this kinematic information implies that tectonic transport was a reverse fault with a minor strike slip component.

The distribution of the $c$-axes along the girdle suggests that the rock deformation was predominantly by prism slip with a contribution of the slip along rhomb and basal planes (Schmid and Casey, 1986). The observation of deformation predominantly by prism slip is in accordance with deformation under upper greenschist to amphibolite facies metamorphic condition as reported in the literature for other deformed belts (e.g. Schmid and Casey, 1986). The result agrees also well with the experimental work and observations on the deformation of quartz by Baeta and Ashbee (1970), Tullis et al. (1973), Schmid and Casey (1986), Masberg et al. (1992), Takamoto et al. (1995), Toru (1996), Kruhl (1996) and others, suggesting that at elevated temperatures prism glide along the $\langle a\rangle$ direction is the dominant deformation mechanism in quartz.

The pole figure for the crystallographic $\{a\}$ prisms exhibits two nearly separated concentrations around linear fabric and the shear direction. The $a$-axis maximum is at the margin of the pole figure with an angle of about $25^{\circ}$ to the foliation plane, thus close to the shear direction.

Preferred orientations of the first order prism $\{m\}$ show a pronounced concentration parallel to the lineation direction. The strongest maxima form an angle of only about $4^{\circ}$, hence indicating a close affinity to the linear fabric. Poles of the positive and negative rhombs $\{r\}$ and $\{z\}$ show a tendency of symmetry in their alignment with respect to the shear plane. Thus, the results obtained conform with the conclusions drawn by Schmid and Casey (1986) for rocks exhibiting similar $c$-axis orientation patterns, i.e. the preferred orientation of the $a$-axis is almost parallel to the shearing direction and first order prism $\{m\}$ orientations are parallel to the lineation direction. 


\section{CONCLUSIONS}

For the studied sample, the preferred orientation patterns of the $c$-axes obtained by optical U-stage measurement and neutron diffraction techniques, respectively, exhibit a remarkable similarity. This finding gives credit to the latter method which, in spite of its inherent intricacies, is much faster and more efficient than the painstaking optical work. The gain of information is illustrated by the $c$-axis results which seem compatible with earlier X-ray analysis findings obtained on rocks deformed under similar conditions. In summary, the present study shows that the investigated rock was predominantly deformed by a prism slip mechanism under the influence of simple shear component. The observed reverse fault with slight sinistral movement reflects the regional tectonic transport direction towards E-ESE and sinistral shearing. This is in accord with the observations by Dürr and Dingeldey (1996).

\section{Acknowledgements}

Financial support by the BMBF under the contract No. 03-KI5BO2 is gratefully acknowledged. $\mathrm{H}$. Ghildiyal acknowledges financial support from the DFG in the framework of the Graduiertenkolleg 144/2 "Geowissenschaftliche Gemeinschaftsforschung in Afrika". Our thanks are also due to $\mathbf{L}$. Ratschbacher and M. Okrusch for critical reading of the manuscript.

\section{References}

Baeta, R.D. and Ashbee, K.H.D. (1970), 'Mechanical deformation of quartz. I. Constant strain rate compression experiments', Philosophical Magazine 22, 601-624.

Bunge, H.J., Wenk, H.-R. and Pannetier, J. (1984), 'Neutron diffraction texture analysis using a $2 \theta$ position sensitive detector', Textures and Microstructures 5, 153-170.

Burg, J.P. and Laurent, P. (1978), 'Strain analysis of a shear zone in a granitoid', Tectonophysics 47, 15-42.

Dingeldey, D.P. (1997), 'Tectono-metamorphic evolutions of the Pan-African Kaoko Belt, NW Namibia', Unpublished Ph.D. Thesis, Mineralogisches Institut, University Würzburg, Germany.

Dürr, S.B. and Dingeldey, D.P. (1996), 'The Kaoko belt (Namibia): Part of a late Neoproterozoic continental scale strike-slip system', Geology 24(5), 503-506.

Franz, L., Romer, R.L. and Dingeldey, D.P. (1999), 'Diachronous Pan-African granulite facies metamorphism (650 Ma and $550 \mathrm{Ma}$ ) in the Kaoko belt, NW Namibia', Eur. J. Mineral. 1, in press.

International Tables for Crystallography (1995), Volume C, 35. 
Kamb, W.B. (1959), 'Theory of preferred orientation developed by crystallisation under stress', J. Geol. 67, 153-170.

Kruhl, H.J. (1996), 'Prism- and basal-plane parallel subgrain boundaries in quartz: a microstructural geothermobarometer', J. Metamorphic. Geol. 14, 581-589.

Masberg, H.P., Hoffer, E. and Hoernes, S. (1992), 'Microfabric indicating granulite-facies metamorphism in the low-pressure central Damara Orogen, Namibia', Precambrian Research 55, 243-257.

Merz, P. (1991), 'Texturanalyse mit Neutronenbeugung an geologisch-mineralogischen Mehrphasen-Proben unter Einsatz eines ortsauflösenden Detektors und der Profilanalyse', Berichte des Forschungszentrums Jülich 2443.

Schäben, H. (1994), 'Diskrete mathematische Methoden zur Berechnung und Interpretation von kristallographischen Orientierungsdichten', DGM Informationsgesellschaft Verlag.

Schäfer, W., Merz, P., Jansen, E. and Will, G. (1991), 'Neutron diffraction texture analysis of multiphase and low-symmetry materials using the position sensitive detector JULIOS and peak deconvolution methods', Textures and Microstructures 14-18, 65-71.

Schäfer, W., Jansen, E., Will, G., Szepesváry, A., Reinartz, R. and Müller, K.D. (1995), 'Update on the Jülich linear and area neutron scintillation detectors', Physica B 213 \& 214, 972-974.

Schäfer, W., Jansen, E., Skowronek, R. and Kirfel, A. (1997), 'The twin-diffractometer SV7 at the FRJ-2 as a workhorse for structure and texture research', Physica $B$ 234-236, 1146-1148.

Schmid, S.M. and Casey, M. (1986), 'Complete fabric analysis of some commonly observed quartz $c$-axis patterns: mineral and rock deformation', American Geophysical Union, Geophysical Monograph 36, 263-286.

Seth, B., Kröner, A., Mezger, K., Nemchin, A.A., Pidgeon, R.T. and Okrusch, M. (1998), 'Archean to Neoproterozoic magmatic events in the Kaoko belt of NW Namibia and their geodynamic significance'. Precambrian Res. 92(4), 341-363.

Simpson, C. (1986), 'Determination of movement sence in mylonites', J. Geol. Education 34, 246-261.

Takamoto, O., Toru, T., Ikuo, H. and Ando-Jun-ichi (1995), 'A new estimate of the conditions for transition from basal to prism [c] slip in naturally deformed quartz' Tectonophysics 250(1-3), 31-46.

Toru, T. (1996), 'Estimate of the physical conditions for deformation based on $c$-axis fabric transitions in naturally deformed quartzite', J. Geol. Soc. Japan 102(3), 211-222.

Tullis, J., Christie, J.M. and Griggs, D.T. (1973), 'Microstructures and preferred orientations of experimentally deformed quartzites', Bull. Geol. Soc. America 84, 297-314.

Turner, F.J. and Weiss, L.E. (1963), 'Structural Analysis of Metamorphic Tectonites', McGraw-Hill, USA, p. 545.

Wenk, H.-R., Kern, H., Schäfer, W. and Will, G. (1984), 'Comparison of neutron and X-ray diffraction in texture analysis of deformed rocks', J. Struct. Geol. 6, 687-692.

Wenk, H.-R., Bunge, H.J., Jansen, E. and Pannetier, J. (1986), 'Preferred orientation of plagioclase - Neutron diffraction and U-stage data', Tectonophysics 126, 271-284.

Wenk, H.-R. and Christie, J.M. (1991) 'Review Paper: Comments on the interpretation of deformation textures in rocks', J. Struct. Geol. 13, 1091-1110. 